Article

\title{
Evaluation of a Thermal Consolidation Process for the Production of Enhanced Technical Fabrics
}

\author{
Angelos Evangelou 1,2, Katerina Loizou ${ }^{1}$, Michalis Georgallas ${ }^{1}$, Ernestos Sarris 1,3®0, Orestes Marangos ${ }^{4}$, \\ Loukas Koutsokeras ${ }^{5}\left(\mathbb{D}\right.$, Stylianos Yiatros ${ }^{4}$, Georgios Constantinides ${ }^{5}\left(\mathbb{D}\right.$, Charalabos Doumanidis ${ }^{1}$ \\ and Vassilis Drakonakis $1,3, *$
}

Citation: Evangelou, A.; Loizou, K.; Georgallas, M.; Sarris, E.; Marangos, O.; Koutsokeras, L.; Yiatros, S.; Constantinides, G.; Doumanidis, C.; Drakonakis, V. Evaluation of a Thermal Consolidation Process for the Production of Enhanced Technical Fabrics. Machines 2021, 9, 143. https://doi.org/10.3390/machines 9080143

Academic Editor:

Dimitrios Manolakos

Received: 27 May 2021

Accepted: 24 July 2021

Published: 28 July 2021

Publisher's Note: MDPI stays neutral with regard to jurisdictional claims in published maps and institutional affiliations.

Copyright: (c) 2021 by the authors. Licensee MDPI, Basel, Switzerland. This article is an open access article distributed under the terms and conditions of the Creative Commons Attribution (CC BY) license (https:/ / creativecommons.org/licenses/by/ $4.0 /)$.
1 AmaDema-Advanced Materials Design \& Manufacturing Ltd., Nicosia 1027, Cyprus; a.evangelou@amdmcomposites.com (A.E.); k.loizou@amdmcomposites.com (K.L.); m.giorgallas@amdmcomposites.com (M.G.); sarris.e@unic.ac.cy (E.S.); h.doumanidis@amdmcomposites.com (C.D.)

2 Department of Mechanical and Manufacturing Engineering, University of Cyprus, Nicosia 2109, Cyprus

3 Department of Engineering, School of Sciences and Engineering, University of Nicosia, Nicosia 2417, Cyprus

4 Department of Civil Engineering and Geomatics, Cyprus University of Technology (CUT), Limassol 3036, Cyprus; orestes.marangos@cut.ac.cy (O.M.); stylianos.yiatros@cut.ac.cy (S.Y.)

5 Department of Mechanical Engineering and Materials Science and Engineering, Cyprus University of Technology (CUT), Limassol 3036, Cyprus; 1.koutsokeras@cut.ac.cy (L.K.); g.constantinides@cut.ac.cy (G.C.)

* Correspondence: vassilis@amdmcomposites.com; Tel.: +357-222-62280

Abstract: Fiber reinforced composites are increasingly used in high value applications. A novel technology (NanoWeld ${ }^{\circledR}$ ) enhancing the structural integrity of the interlayer has demonstrated promising results; however, manufacturing issues related to scalability need to be overcome. The developed technology relies on consolidating thermoplastic nanofiber nonwoven veils onto technical dry fabrics through roll-to-roll ultrasonic welding. The enhanced technical dry fabrics can be further processed as any other technical fabrics for the composites industry. An alternative solution for consolidation is proposed here, based on a thermo-compressive approach to address the scalability issue. A finite element model has been employed to simulate the operating conditions and provide information for optimization of the process. Its results demonstrate that consolidation is achieved rapidly, indicating that the production rate could be accelerated. The quality of enhanced technical dry fabrics produced using the proposed consolidation assembly has been evaluated using scanning electron microscopy as well as mechanical testing of fiber reinforced composites. The mechanical response of such manufactured composites has been compared against benchmark NanoWeld ${ }^{\circledR}$ composites, demonstrating superior performance.

Keywords: CFRP; interlayer enhancement; nanofabrics; fracture toughness; FEM; thermal simulation; consolidation

\section{Introduction}

Over the years, use of fiber reinforced polymers (FRPs) in primary structures of major load-bearing applications has increased. The main drivers behind increasing demand for FRPs in high value applications and industries, such as aerospace and transportation, are the continuous need for fuel economy, structural reliability, and avoidance of environmental pollution. FRPs are perfect candidates to replace and outperform conventional materials due to their higher specific strength. Despite advantages in mechanical performance, however, the anisotropy, complexity of the manufacturing process, and heterogeneity of FRPs typically result in complex damage mechanisms, most often at the interface of laminas (interlaminar region or interlayer) [1]. In order to fully harness the potential of FRPs and meet industry demands, significant efforts have been made over the years to improve interlayer strength and prevent delamination [1]. 
In conventional FRPs, the interlaminar region consists solely of thermosetting resin which lacks strength and toughness. Solutions for strengthening the interlaminar region were explored through development of novel resin systems with toughening agents, and through introduction of thin films or nano-entities in the interlayer (interleaving). Several attempts have been made towards the latter, including, for example: (i) dispersion of nanoparticles in the polymeric matrix of FRPs [2,3]; (ii) dispersion of nanoparticles in the sizing agent of the fibers; (iii) direct growth of nano-entities on the surface of the fibers [4,5]; (iv) spray coating of the fibers [6]; (v) nanocomposite films introduced at the interlayer [7]; (vi) porous nanoparticle preforms introduced at the interlayer [8] and nano-enabled polymer fiber veils as interlayer reinforcement [9].

Although most of these approaches have demonstrated promising potential in suppressing delamination damage, scalability issues hinder their adoption. Work presented here concentrates on utilization of preformed nano-enabled fabrics as interlayer reinforcements. Nanofabrics produced via the method of electrospinning have the potential to overcome scalability issues, as high-volume electrospinning equipment has become commercially available. In addition, modified nanofabrics introduce the potential of multiscale reinforcement by exploiting confluence between the polymer matrix, the fibers (macroscale reinforcement), nanofibers (microscale reinforcement), and nanofiber-embedded nanoparticles (nanoscale reinforcement). In this manner, nano-enabled fabrics enhance not only interlaminar strength and matrix-dominated properties of FRPs, but also the final out-ofplane properties of FRPs. Furthermore, in contrast with most methods listed above, this approach offers minimal disruption of the manufacturing sequence as it is introduced at the lamination stage, with no need for significant alteration of the manufacturing processes in place.

The proposed solution has been commercialized through the registration of a patent for the development of the enhanced technical fabrics, employing a nanofibrous thermoplastic fractal interlayer [10]. NanoWeld ${ }^{\circledR}$ (hereafter referred to as nanofiber enhanced technical fabric) mimics the geometry of feathers to create a scaled geometry from lamina to lamina, resulting in the creation of additional load-transfer mechanisms and leading to enhanced properties and weight reduction of the FRPs [11]. Nanofiber enhanced technical fabric technology consists of three distinct phases, as depicted in Figure 1: Nano-creation of the reinforcement, whereby a non-woven nanofabric reinforced with nanoparticles at the desired concentration is formed via electrospinning; its nano-insertion into the laminate structure, whereby the prepared nanoreinforced nanofabric is placed on the top and bottom of the main technical fabric to be enhanced, creating a sandwich configuration; and finally nano-consolidation of the sandwich configuration, undergoing thermal welding such as ultrasonic welding (Figure 2a) or thermo-compression (Figure 2b), to attach the nanofabric on a technical fabric surface. The quality of this welding relates to the quality of the final dry fabric. The first sub-process, nano-creation of nanofabric via electrospinning, produces the key reinforcement of the final product. Electrospinning yields continuous production of nanofibers, collected on siliconized paper in the form of rolls. Although various nanofabric types (PA6, PVDF, PAN, with addition of carbon nanotubes, or CNTs, as nanoreinforcements) have been employed and optimized for different applications, for the scope of the present paper, all aforementioned nanofabrics have been employed for the theoretical modeling part, whereas for the experimental section only PA6 nanofabrics have been utilized. Key electrospinning processing parameters (polymer solutions, voltage source $(20-25 \mathrm{kV})$, collector distance $(22-25 \mathrm{~cm})$, infusion rate $2-5 \mathrm{~mL} / \mathrm{hr}$, needle diameter $16 \mathrm{G}$ ) have been optimized to form electrospun fibers, using assessment techniques (SEM, tensile test) to inspect the quality of nanofabrics.

The product of the above three-step process is a dry fabric that can be further processed in a similar manner to technical fabrics, through any resin impregnation and curing method. Current nanofiber enhanced technical fabric production efforts employ roll-toroll ultrasonic welding for the nano-consolidation phase (Figure 1). Ultrasonic welding (USW) applies high frequency vibrations on the nanofabric web, inducing localized heating 
and melting of the nanofabric layer. A continuous weld is formed upon cooling of the thermoplastic polymer [12].

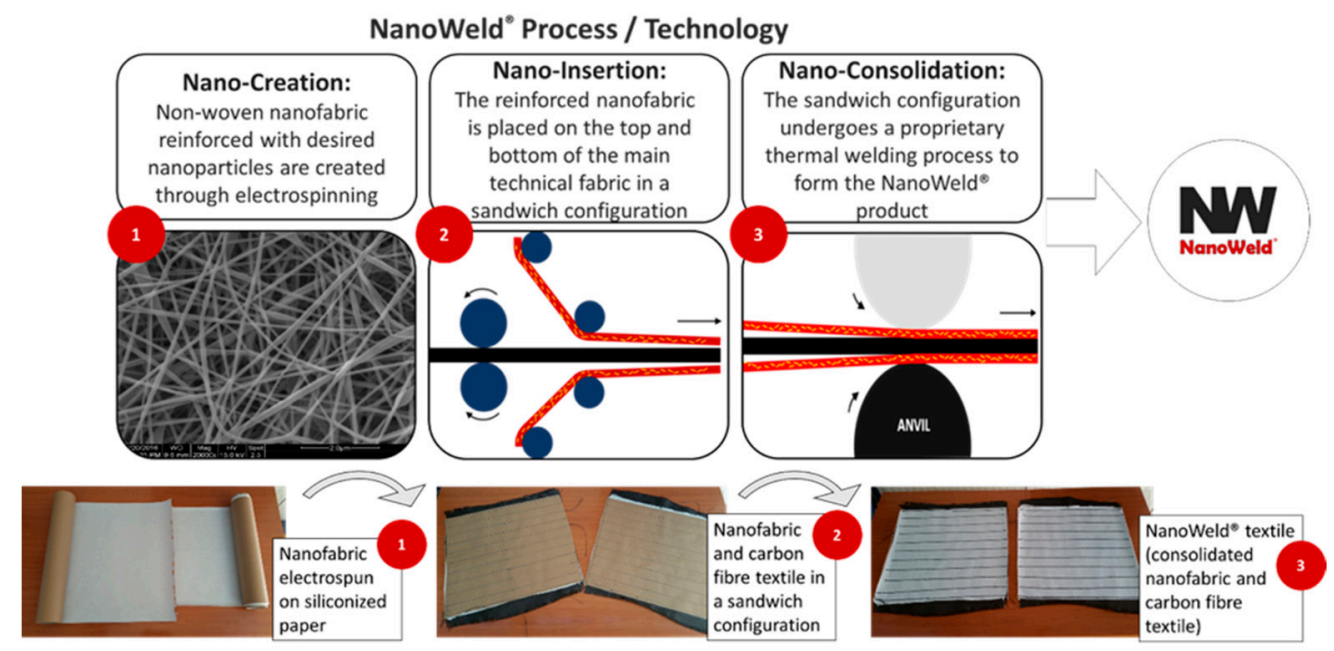

Figure 1. Schematic representation of nanofiber enhanced technical fabric main sub-processes: (1) nano-creation, (2) nano-insertion, and (3) nano-consolidation.

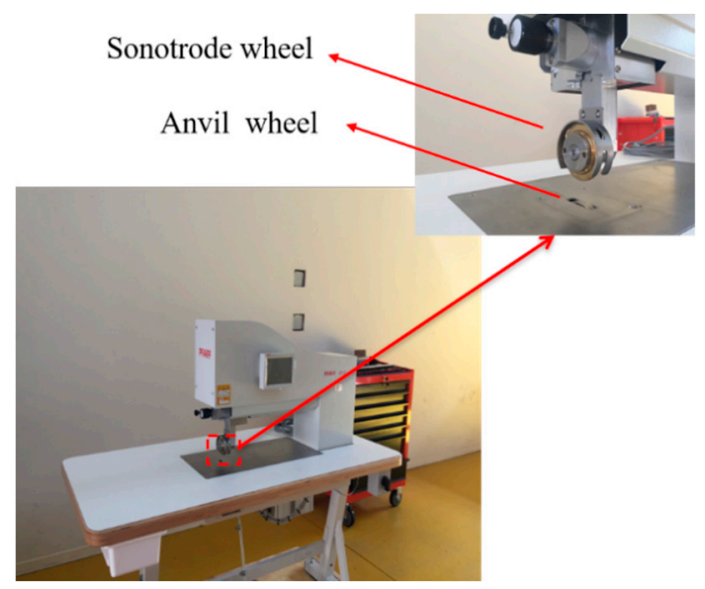

(a)

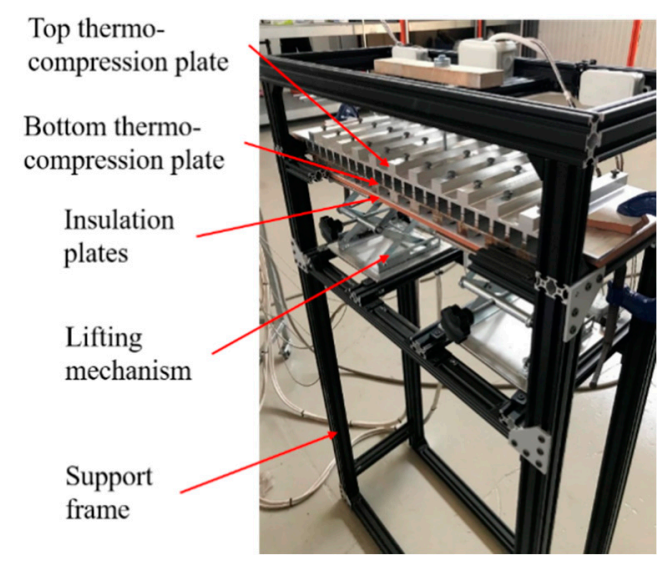

(b)

Figure 2. (a) Ultrasonic welding module. (b) Thermo-compression module with indications of all parts.

The product of the above three-step process is a dry fabric that can be further processed in a similar manner to technical fabrics, through any resin impregnation and curing method. Current nanofiber enhanced technical fabric production efforts employ roll-toroll ultrasonic welding for the nano-consolidation phase (Figure 1). Ultrasonic welding (USW) applies high frequency vibrations on the nanofabric web, inducing localized heating and melting of the nanofabric layer. A continuous weld is formed upon cooling of the thermoplastic polymer [12].

Catering to increasing market needs for FRPs, projected to grow to US $\$ 113$ billion by 2025 despite current market challenges [13], scaling-up of nanofiber enhanced technical fabric fabrication is needed to increase production capacity. To this end, the main challenge in the established nanofiber enhanced technical fabric production process is in scaling up of the nano-consolidation process. Current roll-to-roll USW machines utilize cylindrical sonotrodes with a maximum $25 \mathrm{~mm}$ width, which in turn limit the maximum fabric width that can be processed. In addition, the development of a multi-roll ultrasonic welding machine to consolidate technical fabrics poses additional challenges and setbacks, in terms of space and cost requirements. Similar challenges for the formation of continuous welding 
lines have been also identified in state-of-the-art large scale USW processes using multiple linear sonotrodes and cylindrical anvils [14].

To address such challenges, a thermo-compressive consolidation method has been developed and is examined here, as a more versatile and higher throughput solution, with the ability to produce final products of quality comparable to benchmark ultrasonicfabricated nanofiber enhanced technical fabric. The proposed module consists of a set of heated plates, machined to produce parallel welding lines, and a lifting mechanism for applying pressure on the sandwiched configuration.

Work presented here aims to address the welding scalability problem during the third processing step of nanofiber enhanced technical fabric, which currently uses single roll-to-roll USW to achieve the desired fabric consolidation. This investigation is validated by consolidating a wide range of thermoplastic nanofabrics onto commercially available technical fabrics. In addition, thermal simulation via a finite element model (FEM) is presented to elucidate the consolidation process and support the processing parameter optimization. Finally, quality of the thermo-compression nanofiber enhanced technical fabric product used in FRP composites is assessed in terms of its mechanical response, and compared against FRP composites fabricated with nanofiber enhanced technical fabrics produced via ultrasonic welding.

\section{Materials and Methods}

\subsection{Nano-Consolidation Module Development}

The current consolidation solution utilizes ultrasonic vibration to locally increase the temperature of the thermoplastic nanofabric and induce localized melting. A preselected anvil surface texture forces the molten thermoplastic to partially penetrate the main fiber bed which, upon cooling, solidifies and consolidates in the form of weld islets, as shown in Figure 2a. Nanofiber enhanced technical fabric is then formed when the nanofabric attaches onto the main fiber bed along several parallel welding strips. However, the current USW setup can only weld along a single stripe at a time and scaling up poses a multifaceted challenge. Welding via ultrasonic vibration requires a set of sonotrode and anvil along with a piezoelectric transducer to induce vibrations. As such, to increase the capacity of the manufacturing process, a multi-roll welding process with a sonotrode and anvil for each welding stripe is needed. The complexity of such a system would increase both capital and operating costs which, along with the complex process control and maintenance required, render the solution not viable. In addition, current scale-up solutions of the ultrasonic welding process with a linear extensive sonotrode and cylindrical anvil cannot offer adequate welding quality compared to the roll-to-roll welding line. The thermocompression apparatus suggested simulates the localized heating and pressure provided by the anvil and sonotrode, while simultaneously producing multiple welding lines of desired quality along the width of technical fabrics to be consolidated.

The final prototype is presented in Figure $2 b$, indicating its main components. The prototype design allows simultaneous adjustment of three key parameters needed for control of the consolidation subprocess: (1) line speed, (2) consolidation pressure, and (3) consolidation temperature. Line speed was controlled directly through the winding module shown in the assemblies of Figure 3. The line speeds employed varied from $0.89-2.22 \mathrm{~m} / \mathrm{min}$ for temperature ranges of $180-220^{\circ} \mathrm{C}$. Pressure was applied by vertically moving the bottom plate upwards using two scissor-jack mechanisms, while the top plate was fixed to the support frame. Pressure was measured using a FlexiForce ${ }^{\circledR}$ (Tekscan Inc., Boston, MA, USA) high temperature pressure sensor, and two different measurements were performed at different locations. The measured pressure per tooth was $2.2 \mathrm{kPa}$. The two plates were manufactured using $\mathrm{Al}$ 6063-T6 series to maximize heat transfer while minimizing weight and high temperature oxidation. Each plate comprised 22 protruding teeth, responsible for transferring heat and welding the sandwiched fabrics. Through an iterative process, a specific design was decided for the external surfaces of the metallic plates, to ensure that they did not warp under thermal loading. Heating was supplied to 
each plate by eleven $300 \mathrm{~W}$ ceramic cartridges, inserted into the aluminum plates through drilled holes on their side, as shown in Figure 4 . The holes were drilled with a tolerance of approximately $1 \mathrm{~mm}$ to allow thermal expansion of cartridges as well as of the heating plates. Ceramic tiles were used to insulate the two heating plates from the metallic frame and to minimize heat loss to the environment. Finally, the frame of the machine was assembled using anodized aluminum v-slot extruded profiles, cut to length using a miter saw, and attached together using plate or corner connectors. Following assembly of the components, all electrical and electronic parts were installed and calibrated.

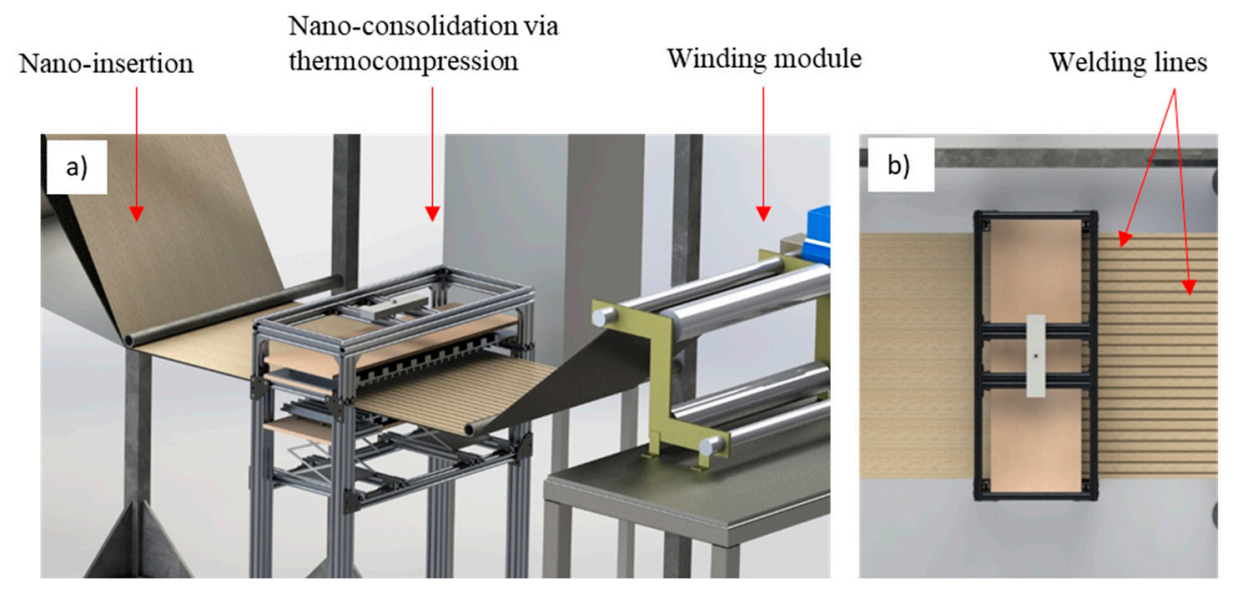

Figure 3. (a) Three-dimensional rendering of the thermo-compression module. (b) Multiple welding lines on the consolidation module of the inserted nanofabric via thermal welding.
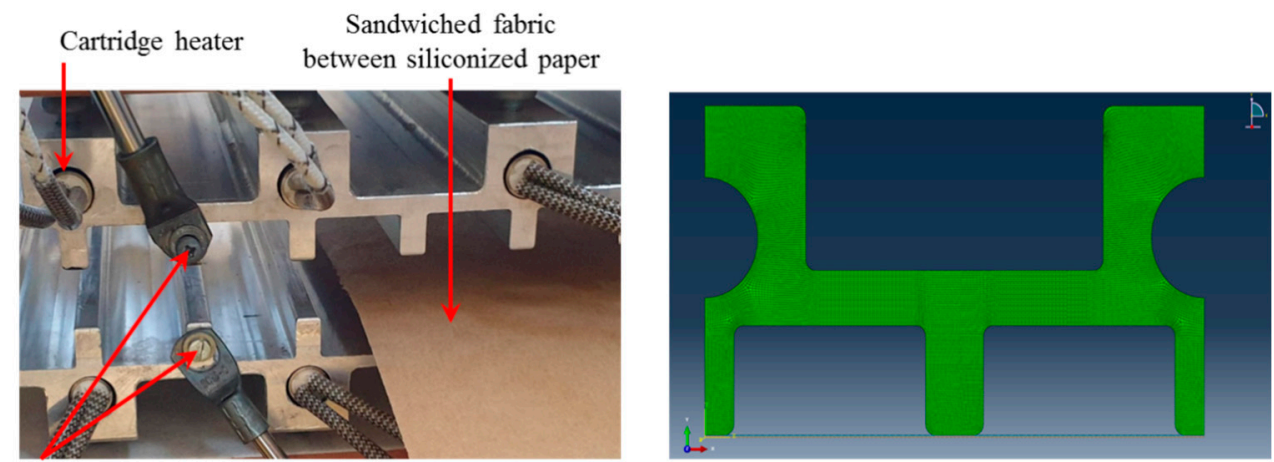

Thermocouple
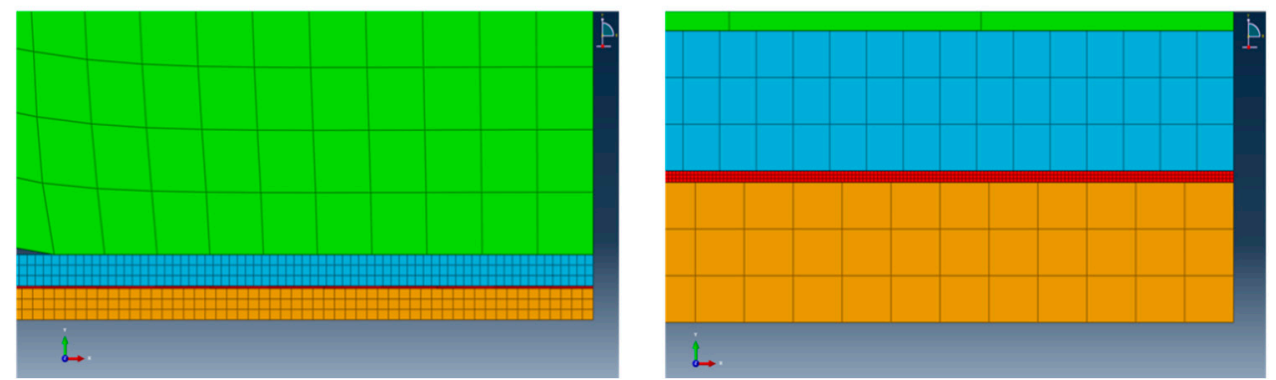

Figure 4. Thermal consolidation apparatus and its finite element model, and that of consolidated materials (green: aluminum platen, light blue: silicon paper, red: nanofabric, orange: carbon fiber fabric).

Implementation of the proposed consolidation module resulted in a custom-made thermo-compression machine, where multiple high quality welding lines could be applied simultaneously, overcoming the ultrasonic welding limitations, and increasing production capacity. The final prototype assembly is shown in the rendering of Figure 3a. The multiple 
welding line capability of the designed consolidation module integrated with nanofiber enhanced technical fabric production line is illustrated in Figure $3 \mathrm{~b}$.

\subsection{Production of Nanofiber Enhanced Technical Fabric}

To examine the system operability and capacity, $50 \mathrm{~m}$ of dry fabric were produced, using commercially available unidirectional carbon fabric (200 gsm ZOLTEK PX35, Toray Group). For the assessment of the newly developed thermo-compression machine, the carbon fabric was sandwiched between two layers of PA6 (polyamide 6) nanofabric prepared in-house via electrospinning. PA6 was selected as interlayer reinforcement for the system, on the basis of quality of consolidation and tensile strength response observed in FRP composites [11]. Properties of the electrospun nanofabric prepared for the present assessment are presented in Table 1.

Table 1. Properties of PA6 nanofabrics.

\begin{tabular}{ccccccc}
\hline Nanofabric & $\begin{array}{c}\text { Average } \\
\text { Thickness } \\
(\boldsymbol{\mu m})\end{array}$ & $\begin{array}{c}\text { Areal } \\
\text { Density } \\
\left(\mathbf{k g} / \mathbf{m}^{\mathbf{2}}\right)\end{array}$ & $\begin{array}{c}\text { Volume } \\
\text { Density } \\
\mathbf{( k g}_{\left.\mathbf{k} / \mathbf{m}^{\mathbf{3}}\right)}\end{array}$ & Porosity(\%) & $\begin{array}{c}\text { Bulk } \\
\text { Density } \\
\left(\mathbf{k g} / \mathbf{m}^{\mathbf{3}}\right)\end{array}$ & $\begin{array}{c}\text { Average } \\
\text { Fiber } \\
\text { Diameter } \\
(\mathbf{n m})\end{array}$ \\
\hline PA6 & 12.15 & 0.0023 & 189.300 & 83.39 & 1140 & $150 \pm 40$ \\
\hline
\end{tabular}

Upon nano-insertion, the sandwich structure consisting of PA6 nanofabric on top and bottom of the procured carbon fabric was consolidated in the system described here. The processing parameters were adjusted in accordance with the nanofabric to be consolidated on the carbon fiber bed, considering its glass transition and melting temperatures. TG was around $48^{\circ} \mathrm{C}$ and TM around $220^{\circ} \mathrm{C}$ [11]. Thus, the temperature range used for the aluminum heated plates was $180-220^{\circ} \mathrm{C}$. The line speed was set to $1-1.55 \mathrm{~m} / \mathrm{min}$. The production line was driven by a motor that was used to wind the consolidated fabric. Thus, the line speed was controlled by a VFD (variable frequency drive), through variation of the rotational speed of the winding shaft. The desired speed in rpm was set by the programmable VFD, which varied the motor input frequency and voltage to control the motor speed and torque. The consolidation time derived from the finite element model was used as a starting point/indication to guide the familiarization and optimization of the operating parameters, including the line speed (see further details in Section 3.1.2).

The designed apparatus demonstrated the capability to process dry fabrics on larger scale, exhibiting the ability to increase the capacity of the system significantly, with the potential to produce six times the output in comparison with the system employing ultrasonic welding consolidation. The speed of welding for the ultrasonic welding was $5 \mathrm{~m} / \mathrm{min}$, whereas for the thermo-consolidation method it was $1.55 \mathrm{~m} / \mathrm{min}$. However, since 22 welding lines could be produced simultaneously, the total welding speed was calculated as $34 \mathrm{~m} / \mathrm{min}$. The produced nanofiber enhanced technical fabric was evaluated in terms of its quality in comparison with the proprietary nanofiber enhanced technical dry fabric. The evaluation of both dry fabric (by SEM observation) and resulting CFRP (in mechanical performance) is presented in the following section.

\subsection{Simulation of Thermal Consolidation}

A finite element model was employed to elucidate the heat transfer mechanism from the unit to the materials to be consolidated. This aimed at providing guidance for the operating parameters for each type of nanofabric employed (PA6, PA6 + CNTs, PAN, and PVDF). Since each nanofabric has different glass transition and melting temperatures, heat transfer was studied for each nanofabric along with localized temperatures at each given operating window. The finite element model was performed to identify any potential limitation prior to operation and alleviate any product failures. 


\subsubsection{Thermal Simulation}

A transient heat transfer analysis was performed to model solid body heat conduction with temperature dependent conductivity and internal energy, after applying convection boundary conditions. For the nonlinear analysis (due to the different materials and properties of the boundary conditions) the Abaqus/Standard, a finite element software package that utilizes an iterative scheme to solve nonlinear heat transfer problems, was utilized. The scheme uses the Newton method with some modification to improve stability of the iteration process in the presence of highly nonlinear latent heat effects. The assumptions of the uncoupled transient heat transfer solution are as follows:

- The temperature field calculated did not take into consideration the stress/deformation in the materials being modeled.

- The solution combined conduction and boundary convection modeling.

- A readily available heat transfer element (DC2D4) suited for this purpose was used for the transient heat transfer analysis.

- Thermal interactions such as conductance between different materials was resolved by creating contact surfaces, which allow for relaxation of the one-to-one node correspondence constraint, and model the three orders of magnitude difference in the length scale of simulated materials.

- A fully transient nonlinear heat transfer analysis was performed in two steps: (1) preheat the machine and (2) allow for heat transfer to proceed in the materials.

\subsubsection{Geometry}

The heat transfer model was constructed based on the actual dimensions of the thermal consolidation apparatus, as shown in Figure 4. The materials of the system were: (1) the 6063-T6 aluminum plate shown with green color, (2) siliconized paper shown with light blue color, (3) nanofabric shown with red color, and (4) carbon fiber fabric shown with orange color. The materials are shown together with heat sources (cartridges) and thermocouples to measure temperature during conduction from the heat source through the aluminum plate and into the sandwiched materials to achieve bonding. Figure 4 also presents the symmetrical finite element model in full form, with details in the finite element discretization of different materials. The model presented in Figure 4 (all four regions: aluminum plate, siliconized paper, nanofabric, and carbon fabric) was constructed with a total of 75,331 elements. The Abaqus element type that was considered for all regions is DC2D4, as it ranks as the most convenient for transient heat transfer between different materials.

\subsubsection{Material Properties}

The material properties used for the simulation were obtained from the material manufacturers and the literature [15-24]. Table 2 summarizes the material data used for simulations. The materials included: (i) aluminum plate, (ii) carbon fibers, (iii) silicon paper, (iv) polyamide 6 (PA6), (v) polyacrylonitrile (PAN), (vi) polyvinylidene (PVDF), and (vii) polyamide 6 and carbon nanotube (PA6 + CNT). It is important to note that all conductivity values of fibers were along the transverse direction.

Table 2. Specimen description for each test performed.

\begin{tabular}{cccccc}
\hline Test & $\begin{array}{c}\text { Specimen } \\
\text { Geometry }\end{array}$ & $\begin{array}{c}\text { Specimen } \\
\text { Length }(\mathbf{m m})\end{array}$ & $\begin{array}{c}\text { Specimen } \\
\text { Width }(\mathbf{m m})\end{array}$ & $\begin{array}{c}\text { Specimen } \\
\text { Thickness } \\
\text { (mm) }\end{array}$ & $\begin{array}{c}\text { Number } \\
\text { of Layers }\end{array}$ \\
\hline $\begin{array}{c}\text { Fracture Mode I } \\
\text { Flexural }\end{array}$ & $\begin{array}{l}\text { Rectangular } \\
\text { Rectangular }\end{array}$ & 200 & 25 & 4.5 & 22 \\
Compression & Rectangular & 154 & 13 & 4 & 19 \\
\hline
\end{tabular}




\subsection{Material Evaluation}

\subsubsection{Dry Fabric Level}

At dry fabric level, successful consolidation of the top and bottom nanofabric layers with the carbon fiber bed was investigated via scanning electron microscopy (SEM). SEM was performed at different locations, using a Quanta microscope from FEI, to examine the quality of consolidation, as well as the degree of penetration of the nanofabric within the main fiber bed, along with the condition of the nanofabric adjacent to the welds.

\subsubsection{Carbon Fiber Reinforced Polymer (CFRP) Level}

Thermo-compression nanofiber enhanced CFRP composite plates were fabricated to evaluate their mechanical response against UW nanofiber enhanced CFRP plates. Mechanical tests performed included fracture toughness mode I, flexural and compression strength tests. CFRP plates were manufactured via vacuum assisted hand lay-up method using the R2930/H303 epoxy resin system. Reinforcement layers were stacked, with uniform spreading of resin in between each layer. Then vacuum bagging was employed to distribute the resin and remove excess. For all samples, the orientation of the fibers was at $0^{\circ}$. To achieve maximum strength, a two-step curing followed; under vacuum for $24 \mathrm{~h}$ at ambient conditions, followed by thermal annealing at $55^{\circ} \mathrm{C}$ for $6 \mathrm{~h}$. Upon curing, specimens for each test described below were routed using CNC milling. Table 2 tabulates the specimen geometry, size, and the number of layers employed to fabricate the specimens.

\subsubsection{Fracture Toughness Mode I Tests}

Fracture toughness was tested following the standard test method for mode I interlaminar fracture toughness of unidirectional fiber-reinforced polymer matrix composites described by ASTM D5528. Double cantilever beam (DCB) specimens were tested under crack opening mode, in which the delamination faces of the specimen open away from each other. A non-adhesive insert was placed at the mid-plane of the specimens to serve as a delamination (crack) initiator. Loading was applied to the specimen using a custom-made tensile testing machine described in [11], using piano hinges carrying a $250 \mathrm{~N}$ load cell, as seen in Figure 5. Due to the lack of sensitivity of the load cell on the UTM, a smaller load cell $(250 \mathrm{~N})$ was used to capture the response. Firstly, the specimen was loaded to an increment of delamination crack growth of 3 to $5 \mathrm{~mm}$ with a crosshead rate of $1-5 \mathrm{~mm} / \mathrm{min}$. Then, the specimen was unloaded with a rate of up to $25 \mathrm{~mm} / \mathrm{min}$ and reloaded at the same initial rate, to a crack length of $50 \mathrm{~mm}$. The delamination crack length was measured with the aid of a scale with $1 \mathrm{~mm}$ markings, attached below the midline delamination initiator. Advance of the delamination was monitored using a digital image correlation (DIC) setup, equipped with two $5 \mathrm{MP}$ cameras with $16 \mathrm{~mm}$ focal length lenses, which provided approximately $60 \mu \mathrm{m}$ spatial resolution (Q-400, Dantec Dynamics, Skovlunde, Denmark).

\subsubsection{Flexural Strength Tests}

Flexural properties of the test specimens were examined by a three-point bending test following ASTM D7246, using a Lloyds Universal Testing Machine with a $150 \mathrm{kN}$ load cell (LR 150K Plus, AMETEK, West Sussex, UK). During the test, rectangular crosssection samples were deflected at a constant rate of $1.0 \mathrm{~mm} / \mathrm{min}$ (Figure 5). The specimen dimensions were set such that the thickness to span length ratio was 1:32, to limit outof-plane shear deformations and avoid unacceptable types of short beam failure modes. Accordingly, the span length was set at $134.4 \mathrm{~mm}$. Force displacement data were obtained and converted to flexural strength and flexural modulus. 


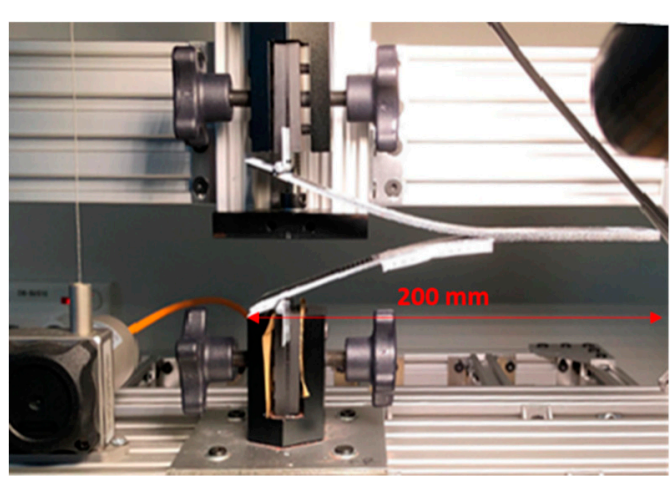

(a)

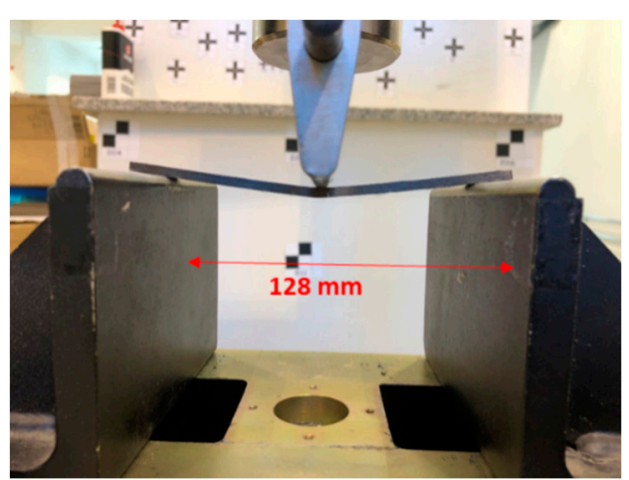

(b)

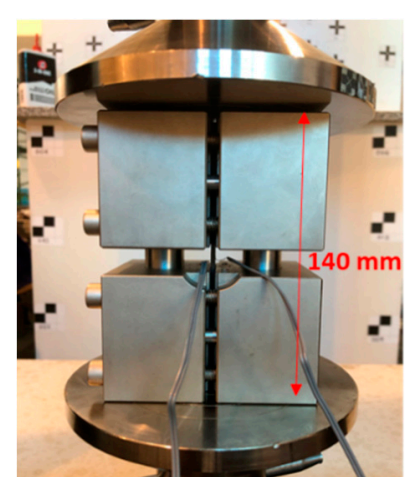

(c)

Figure 5. (a) Crack opening and crack location was measured by the attached scale with the zero-mark placed at the initial crack location. (b) Three-point bending setup for measuring strength in flexure. Specimen was placed between two supports while a loading nose applied the load at midspan. (c) Specimen placement in loading fixture between compression platens. Strain gauges were placed at the front and back of the specimen.

\subsubsection{Compression Strength Tests}

Compression strength tests were performed in accordance with ASTM D6641 using a combined loading compression (CLC) test fixture. A compressive force was introduced to the specimen through combined end and shear loading via a test fixture which consisted of four grips and two alignment rods, as seen in Figure 5. The specimen was placed between the compression plates of the $150 \mathrm{kN}$ Lloyds Universal Testing Machine and loading was applied at a crosshead rate of $0.2 \mathrm{~mm} / \mathrm{min}$. The specimens used were $140 \mathrm{~mm}$ long, $13 \mathrm{~mm}$ wide and had a $13 \mathrm{~mm}$ of unsupported gauge length when installed in the fixture. The specimen thickness was set to $2 \mathrm{~mm}$ to avoid failure by Euler buckling. Two linear strain gauges (FLAB-2-11-3LJC-F, Tokyo Measuring Instruments Laboratory Co., Ltd., Tokyo, Japan) were attached to the front and back faces of the specimens, within the unsupported gauge length, to monitor any excessive bending of the specimens and detect possible failure by buckling. Attachment of strain gauges was necessary as failure mechanisms were not evident by the force-displacement curve. Compression tests were rejected if Euler buckling was present, or the percentage bending exceeded $10 \%$, which was defined as:

$$
\% \text { Bending }=\frac{\epsilon_{1}-\epsilon_{2}}{\epsilon_{1}+\epsilon_{2}} \times 100
$$

$\epsilon_{1}=$ strain in the loading direction at the front face

$\epsilon_{2}=$ strain in the loading direction at the back face

\section{Results and Discussion}

\subsection{Simulation of Thermal Consolidation}

3.1.1. Boundary Conditions and Solution Steps: (A) Preheating of Aluminum Plate

From the description of the model in Section 2.3.2, it is evident that a portion of the heat plate has been used because of the geometrical symmetry which makes feasible the simulation in a computationally efficient manner. The boundary condition for the heat source applied at the left and right semicircular portions of the geometry was measured in the laboratory, by fitting a thermocouple at the teeth between the two plates. In this way it was ensured that the accurate magnitude was measured experimentally of the temperature that was transferred from the aluminum platen to the material system below. Of course, this magnitude presents periodicity (as a function of time) but for the simulation this magnitude was applied for only one cycle, because temperature equalizes with the boundary condition applied over the first cycle. At this point it is considered important to mention that there is no estimation of the simulated error caused by the edge effect because there is no information for the heat that was lost due to the edge boundaries 
in the laboratory. However, the main purpose of the models was to simulate how heat was transferred between the material systems and to predict the appropriate temperature magnitude for thermal consolidation, not to determine the heat losses.

As explained, the boundary condition used for simulations was the actual temperature profile as a function of time, measured by a thermocouple at the teeth of the machine (shown with red arrow markers in). This boundary condition was time dependent and ranged between $13.2{ }^{\circ} \mathrm{C}$ and $220{ }^{\circ} \mathrm{C}$, and it took about $375 \mathrm{~s}$ to reach this maximum temperature. This profile was applied at the semicircles at the left and right of the aluminum plate, as depicted in Figure 6. The model was then allowed to run for $550 \mathrm{~s}$ (for $175 \mathrm{~s}$ maintaining the max temperature at $220^{\circ} \mathrm{C}$ ) to warm up the aluminum plate as a first step, matching well with the experimental measurement of the thermocouple. All simulations were performed at the temperature of $220^{\circ} \mathrm{C}$ in order to enable comparisons between the different nanofabric systems. However, experimentally the temperature used was a function of the material properties. Moreover, for presentation purposes it was chosen to present the computational results with respect to the melting point of PA6. Figure 6 also presents the various nodes on the aluminum plate to extract the temperature distribution as a function of time (i.e., temperature history analysis). The temperature history profiles at all sampling nodes considered on the aluminum plate were in excellent agreement with the experimental measurements.

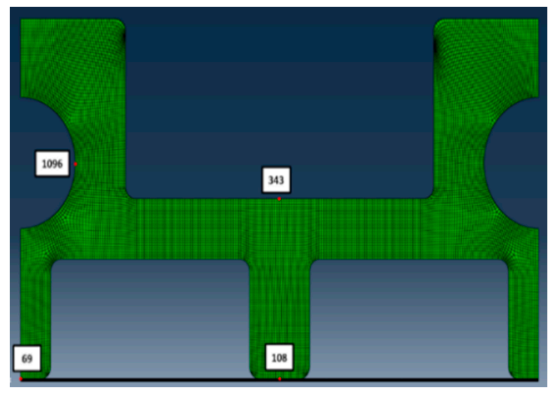

(a)

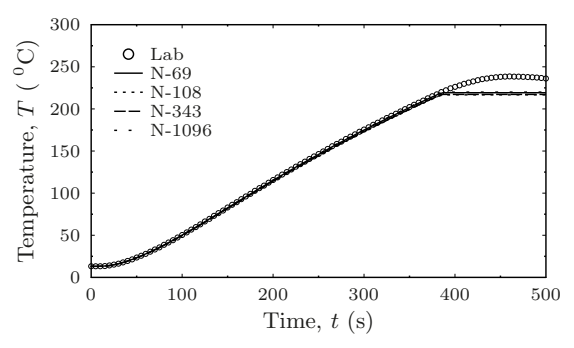

(b)

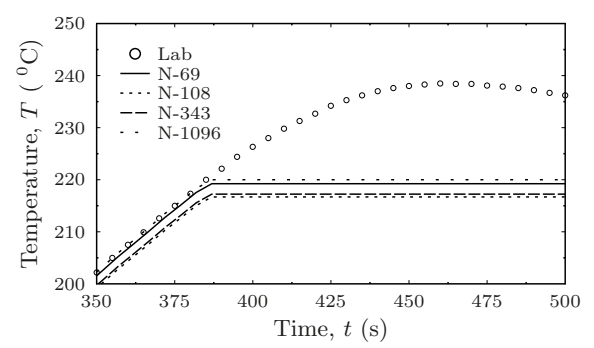

(c)

Figure 6. (a) Sampling nodes for temperature analysis. (b) Temperature profiles of aluminum plate nodes. (c) Detailed area to show the delayed temperature profiles.

A negligible delay was observed (Figure 6) in the temperature profiles between node 1096 (at the cartridge location) and 108 (in the center plate tooth). This delay was expected due to the time it took for heat to reach from the cartridge to the center of the plate tooth. The time increment for resolving the transient heat transfer was of the order of $1 \times 10^{-3}$ s. With these results, it was ensured that the expected temperature was transferred from the cartridge to contact points of the plate correctly and also relatively fast, due to the high conductivity of aluminum plates. In any rate, a pre-heating time of $500 \mathrm{~s}$ is also a standard experimental practice to reach the desired value of $220^{\circ} \mathrm{C}$. Therefore, successful application of the boundary conditions to the numerical model was verified. The next step was to transfer this temperature uniformly in the materials under processing and perform the transient thermal simulation analysis in them.

\subsubsection{Boundary Conditions and Solution Steps: (B) Transient Heat Transfer in the Material System}

In this second step, the materials (carbon fiber, silicon paper, and nanofabric) allowed heat transfer, while at the same time the temperature boundary condition was kept constant at its highest value at the cartridge location. In the first step, pre-heating of the aluminum plate was achieved while all other materials were kept deactivated. Once the aluminum plate reached the desired temperature, the other materials were activated, and transient heat was allowed to diffuse in them as a second step. The solution end time for this second step was allowed to be large, with the main purpose to allow for the simulation to 
reach steady state thermal conditions. The major simulation challenge was the different dimensions (three orders of magnitude difference) of the various parts involved (aluminum platen, silicon paper, nanofabric, and carbon fiber). The classical meshing method dictating a one-to-one correspondence between the nodes of the different parts generating excessive numbers of elements was avoided by creating surfaces in the upper and lower ends of each part, and then application of tie constraints to all parts enabled them to perfectly bond, allowing smooth heat transfer through the different materials during thermal consolidation, as shown in Figure 4.

The following analysis involves the temperature history analysis in preselected nodes to plot the temperature history profiles. These nodes were located at the boundaries of the model (boundary node), below the central teeth (center node), and in the middle of the two teeth (middle node). In the material, all nodes were in the middle of the nanofabric.

Figure 7 demonstrates the temperature history analysis at the center location stated earlier for all different materials considered (PA6, PA6+CNT, PAN, and PVDF-Table 3). It is apparent that all materials reached the maximum temperature at the center node (26007) at $0.004 \mathrm{~s}$, indicating rapid transient heat transfer. It is noted that the time recorded started from $500 \mathrm{~s}$, accounting for the time required to achieve steady state thermal conditions (in the first step). Comparing heat transfer in different nanofabrics employed, the slowest heat transfer was observed for PAN, followed by PVDF, PA6, and PA6+CNTs, exhibiting a distinctly different behavior, as the boundary condition was reached almost instantaneously for the time increment selected to resolve transient heat transfer.

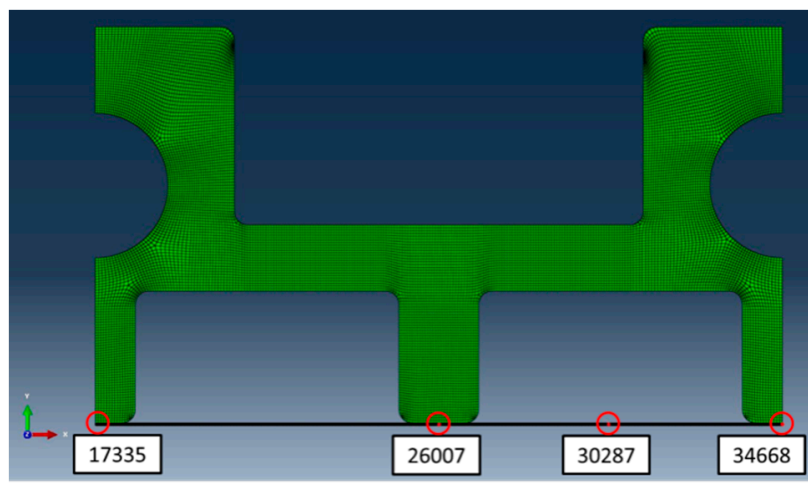

(a)

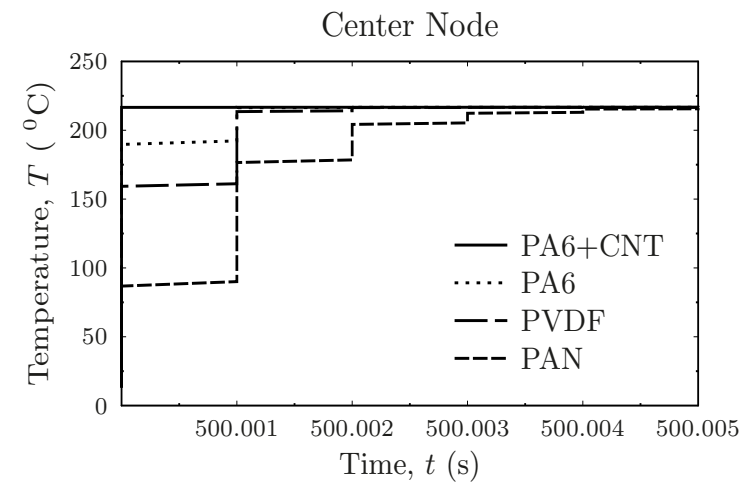

(b)

Figure 7. (a) Sampling nodes for analysis of nanofabrics. (b) Transient heat transfer at nanofabric node 26007.

Figure 8a presents the temperature history analysis at the middle node. PA6, PAN, and PVDF demonstrated the same behavior once heat was transferred through the material bed, reaching the maximum temperature of the boundary condition in $4 \mathrm{~s}$. Like the first node, PA6+CNT behaved in a different manner. PA6+CNTs ramped to the final temperature profile rather faster than the other materials examined. This effect can be attributed to the intrinsic conductivity values considered in the model (Table 3). Finally, Figure 8b shows the temperature history of the boundary node for all materials. It is evident that transient heat transfer at the boundary node behaved essentially the same as at the center node (Figure $7 \mathrm{~b}$ ). At this point it is considered important to mention that the temperatures profiles in Figures $7 \mathrm{~b}$ and $8 \mathrm{~b}$ are not smooth but piecewise because of the time resolution on the $x$-axis. A closer look shows that the temperature boundary condition ramped to final value in the first $0.005 \mathrm{~s}$. 
Table 3. Summary of material data used in the simulations.

\begin{tabular}{|c|c|c|}
\hline Data & Material & Units \\
\hline \multicolumn{3}{|c|}{ Aluminum Plate [15] } \\
\hline Conductivity & 0.205 & $\mathrm{~W} /\left(\mathrm{mm}-{ }^{\circ} \mathrm{C}\right)$ \\
\hline Density & 0.0000027 & $\mathrm{~kg} / \mathrm{mm}^{3}$ \\
\hline Specific Heat & 900 & $\mathrm{~J} /\left(\mathrm{kg}-{ }^{\circ} \mathrm{C}\right)$ \\
\hline \multicolumn{3}{|c|}{ Carbon fibers [16] } \\
\hline Conductivity & 0.00025 & $\mathrm{~W} /\left(\mathrm{mm}-{ }^{\circ} \mathrm{C}\right)$ \\
\hline Density & $2 \times 10^{-6}$ & $\mathrm{~kg} / \mathrm{mm}^{3}$ \\
\hline Specific Heat & 710 & $\mathrm{~J} /\left(\mathrm{kg}-{ }^{\circ} \mathrm{C}\right)$ \\
\hline \multicolumn{3}{|c|}{ Silicon Paper $[17,18]$} \\
\hline Conductivity & 0.13 & $\mathrm{~W} /\left(\mathrm{mm}-{ }^{\circ} \mathrm{C}\right)$ \\
\hline Density & $2.33 \times 10^{-6}$ & $\mathrm{~kg} / \mathrm{mm}^{3}$ \\
\hline Specific Heat & 700 & $\mathrm{~J} /\left(\mathrm{kg}-{ }^{\circ} \mathrm{C}\right)$ \\
\hline \multicolumn{3}{|c|}{ Polyamide 6 (PA6) $[19,20]$} \\
\hline Conductivity & 0.00028 & $\mathrm{~W} /\left(\mathrm{mm}-{ }^{\circ} \mathrm{C}\right)$ \\
\hline Density & $1.14 \times 10^{-6}$ & $\mathrm{~kg} / \mathrm{mm}^{3}$ \\
\hline Specific Heat & 1700 & $\mathrm{~J} /\left(\mathrm{kg}-{ }^{\circ} \mathrm{C}\right)$ \\
\hline \multicolumn{3}{|c|}{ Polyacrylonitrile (PAN) [21,22] } \\
\hline Conductivity & $5.00 \times 10^{-5}$ & $\mathrm{~W} /\left(\mathrm{mm}-{ }^{\circ} \mathrm{C}\right)$ \\
\hline Density & $1.18 \times 10^{-6}$ & $\mathrm{~kg} / \mathrm{mm}^{3}$ \\
\hline Specific Heat & $1.29 \times 10^{3}$ & $\mathrm{~J} /\left(\mathrm{kg}-{ }^{\circ} \mathrm{C}\right)$ \\
\hline \multicolumn{3}{|c|}{ Polyvinylidene (PVDF) $[23,24]$} \\
\hline Conductivity & $2.00 \times 10^{-4}$ & $\mathrm{~W} /\left(\mathrm{mm}-{ }^{\circ} \mathrm{C}\right)$ \\
\hline Density & $1.78 \times 10^{-6}$ & $\mathrm{~kg} / \mathrm{mm}^{3}$ \\
\hline Specific Heat & 1300 & $\mathrm{~J} /\left(\mathrm{kg}-{ }^{\circ} \mathrm{C}\right)$ \\
\hline \multicolumn{3}{|c|}{ Polyamide $6+$ Carbon Nanotube $($ PA6 + CNT) [20] } \\
\hline Conductivity & 0.0035 & $\mathrm{~W} /\left(\mathrm{mm}-{ }^{\circ} \mathrm{C}\right)$ \\
\hline Density & $8.00 \times 10^{-7}$ & $\mathrm{~kg} / \mathrm{mm}^{3}$ \\
\hline Specific Heat & 686.1275 & $\mathrm{~J} /\left(\mathrm{kg}-{ }^{\circ} \mathrm{C}\right)$ \\
\hline CNT diameter & 4 & $(\mathrm{~nm})$ \\
\hline
\end{tabular}

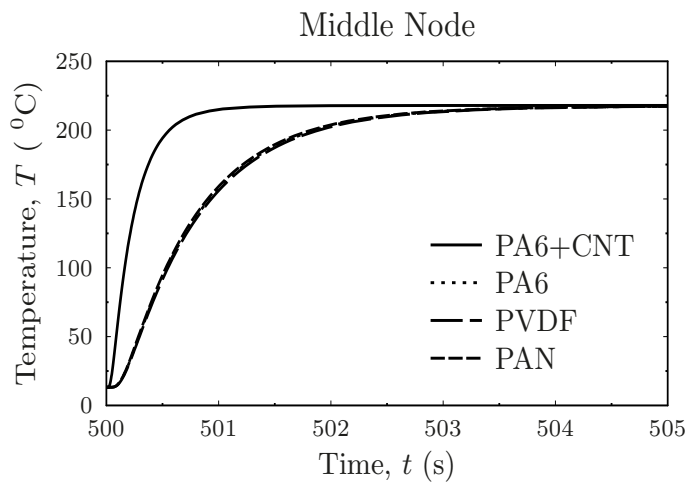

(a)

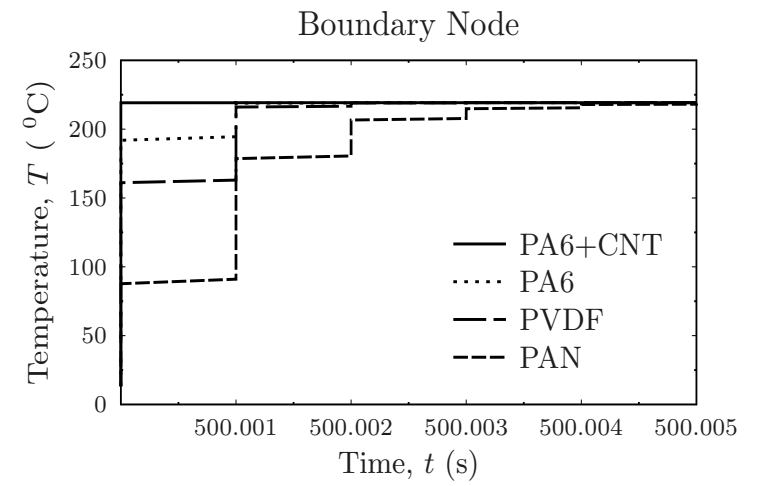

(b)

Figure 8. (a) Transient heat transfer at middle node 30,287. (b) Transient transfer at boundary node 34,668.

In the next part of this analysis, transient heat transfer profiles were determined after selecting two nodes, at the left end $(17,335)$ and right end $(34,668)$ corner of the nanomaterial, creating a section. The nodes were located at the middle of the nanofabric. 
Figure 9 illustrates the temperature profile at the created section between two nodes as a function of distance $T=f(L)$ for all materials considered.

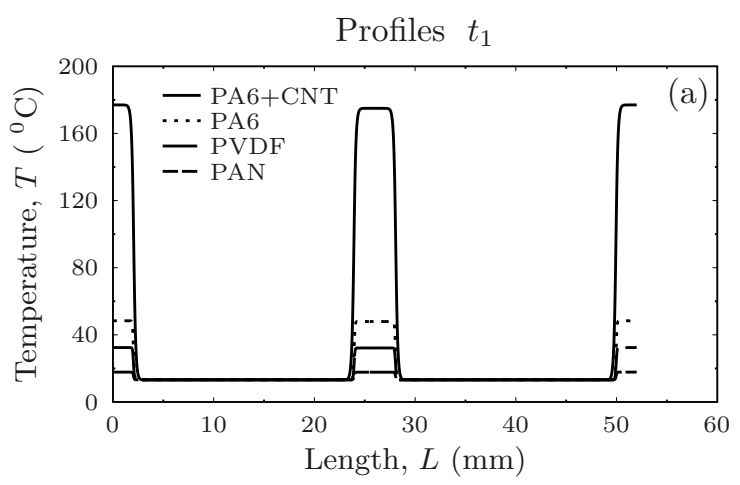

(a)

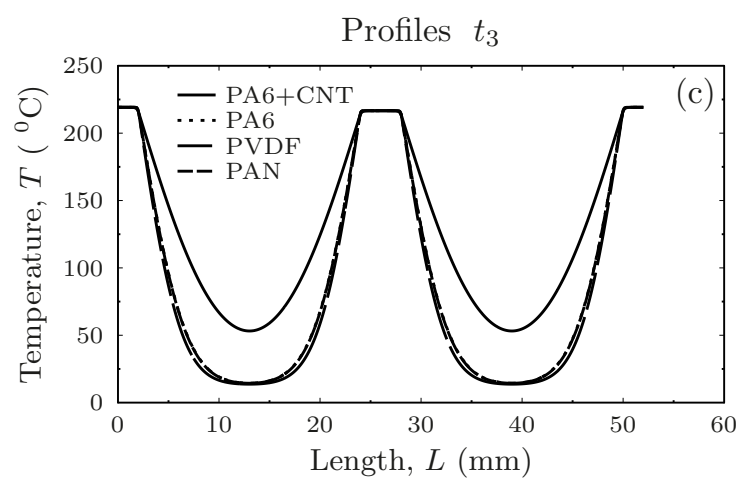

(c)

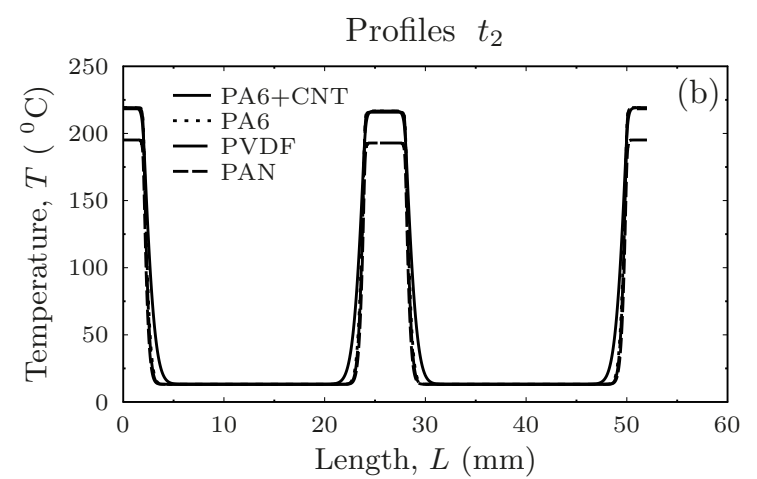

(b)

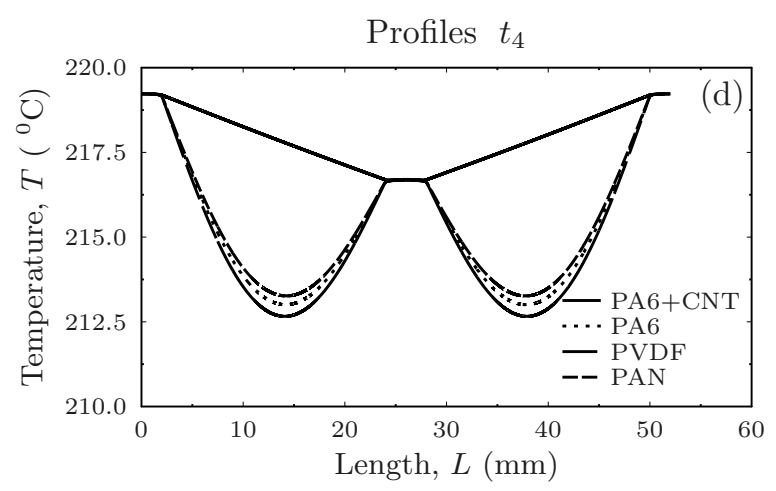

(d)

Figure 9. Temperature profiles for all materials at (a) $1 \times 10^{-4}$ s., (b) $2 \times 10^{-3}$ s., (c) $9 \times 10^{-2}$ s., (d) $3 \mathrm{~s}$.

As seen in Figure 9a, at $\mathrm{t}<10^{-4} \mathrm{~s}$, the temperature started to increase at the teeth, whereas the initial temperature condition was sustained in the materials between the teeth. At a later stage (Figure 9b), the temperature below the teeth reached the maximum value of the boundary condition $\mathrm{T}=220^{\circ} \mathrm{C}$. The maximum temperature was obtained first for PA6+CNT, followed by PA6, PVDF, and finally by PAN. At time $9 \times 10^{-2} \mathrm{~s}$ (Figure 9c), the temperature profile increased between the teeth, thereby suggesting lateral heat transfer, and started increasing towards the maximum applied boundary condition $\mathrm{T}=220{ }^{\circ} \mathrm{C}$. Finally, in Figure 9d and at $\mathrm{t}=3 \mathrm{~s}$ the temperature profile in all materials equalized with the boundary condition. The apparent differences observed are due to material conductivities. In other words, the time required to reach steady state heat transfer conditions was different for each model due to the material data differences. However, this difference was negligible, since due to the small-scale regions all phenomena associated with transient heat transfer diminished within 1-2 s. The most notable difference was for PA6+CNT, which is highly conductive and transfers heat faster compared to other nanofabric materials. The value of thermal conductivity considered in the simulations for the PA6+CNT nanocomposite was considered in [20]. It is also important to mention that in Figure $9 \mathrm{~d}$, the temperature profile appears to decrease in the middle "tooth". If one takes a closer look, this perturbation is attributed to the resolution of the $y$-axis showing differences in the temperature profile within variations of $2{ }^{\circ} \mathrm{C}$ at a temperature of $220{ }^{\circ} \mathrm{C}$, which can be safely assumed to equalize with the boundary condition considered in the simulation.

Figure $10 \mathrm{~b}$ shows in detail the nonlinear heat transfer in various materials considered for this simulation. From the thermal simulation, it is apparent that heat was transferred in both directions vertically (y-direction) and horizontally (x-direction). The temperature transfer in the model appears to follow the fundamental Fermat principle from wave 
theory, which is the path with the least resistance or the fastest route. This path was below the teeth platen. Of course, lateral heat was observed but the vertical heat transfer dominated compared to the longitudinal. As soon as the boundary condition $\mathrm{T}=220^{\circ} \mathrm{C}$ was reached, then the longitudinal heat transfer became more active and most probably was due to the confined space of the material regions. When the three heat fronts in the various materials equated, then diffusion in all materials was more profound and as a direct result, temperature caused an increase in the profiles on the selected cross section to plot the temperature distributions. However, due to the small size of the simulated regions, transient heat transfer was completed within the first $5 \mathrm{~s}$ (even if extreme heat losses are considered, the time needed for heat to transfer does not change much, due to the dependency of transient heat transfer on the material parameters). The model thus demonstrates that conditions required for consolidation were obtained promptly.

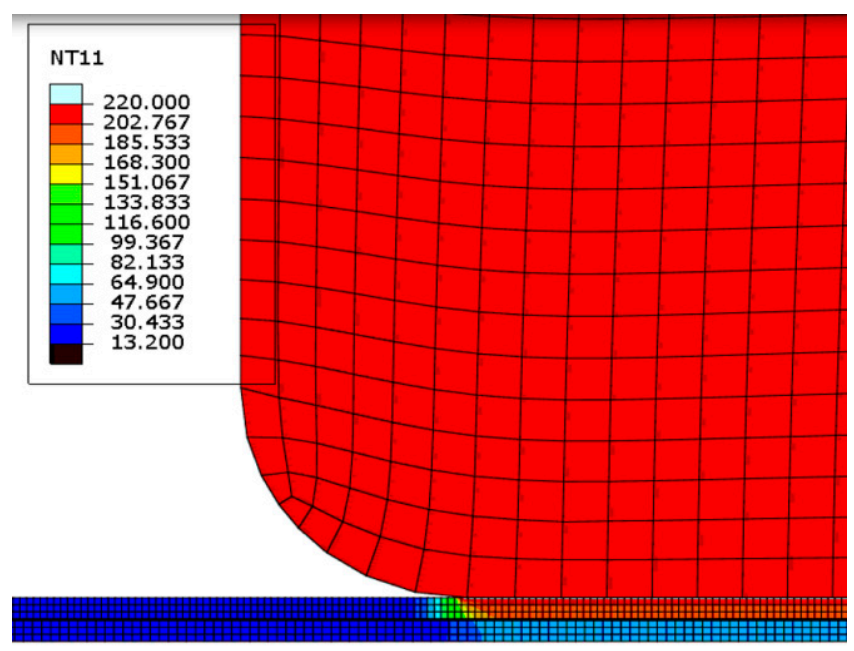

(a)

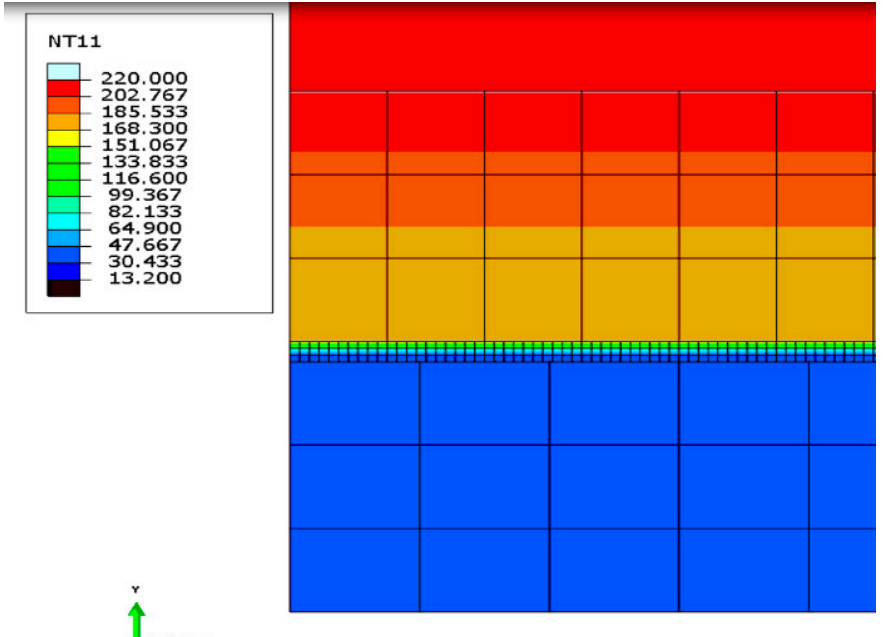

(b)

Figure 10. (a) Transient temperature distribution (central). (b) Detailed distribution (boundary).

The manufacturing setup shown in Figure 10 is for PA6 and the total simulation time was $500.0025 \mathrm{~s}$ (500 s heating the platen and $0.0025 \mathrm{~s}$ for transient heat transfer in the material system). These results of the developed finite element model aided in the selection of processing parameters for nanofiber enhanced technical fabric production, and more specifically, the line speed utilized to consolidate the "nanofabric-fabric-nanofabric" sandwich structure. The respective line speed was calculated for each simulated nanofabric system. These values were subsequently used as starting points for the familiarization procedure with the thermo-compressive consolidation apparatus, which was followed by an optimization procedure.

The consolidation time derived from the finite element model was used as a starting point/indication to guide the familiarization and optimization of the operating parameters, specifically the line speed. A parametric study was conducted and consolidation was investigated at rotational speeds that translated at different line speeds. Consolidation was evaluated via SEM to assess bonding quality between the nanofabric and the fiber bed. Nevertheless, from the simulation results it is apparent that insulation of the system to minimize heat losses and employment of higher torque and rotational speed motors can further accelerate the production speed. 


\subsection{Evaluation of the Thermal Consolidation Module \\ Dry Fabric Level}

Dry fabrics, for the scope of material evaluation, were produced using PA6 nanofabrics. The consolidated fabrics were produced at temperature of $200{ }^{\circ} \mathrm{C}$ and line speed of $1.55 \mathrm{~m} / \mathrm{min}$, at pressure of $2.2 \mathrm{kPa}$ at each tooth.

Figure 11 depicts the SEM image of the weld, along with a magnification of the marked area. As demonstrated, the nanofabric melted locally (losing its nanofibrous structure) (Figure 11b) and penetrated the carbon fiber bed, demonstrating attachment between the nanofabric and the carbon fiber bed following thermo-compressive consolidation. The nanofabric melted, covering carbon fiber tows and penetrating the carbon fiber bed. Upon cooling, the molten nanofabric solidified, resulting in bonding and attachment between the nanofabric and the carbon fabric. The adjacent nanofabric appeared to be retaining its initial porous structure (in the form of nanofiber assembly, Figure 12b) as observed in Figure 12a, with an intermediate region between the weld and adjacent nanofabric. With the simulation results in mind, indicating rapid thermal conduction within the nanofibercarbon fiber bed, this ensures that the structure of the nanofabric is preserved. This is vital since the nanofabric as a nanofiber assembly is a porous structure, permitting penetration of epoxy resin upon processing to manufacture fiber reinforced composites. If the geometrical characteristics are altered due to heat transfer within the materials, this will compromise the quality of dry fabric, limiting its processability at the composite level.

In comparison, the weld produced via ultrasonic welding consolidation is presented in Figure 13. As depicted in Figure 13, in both welding methods (thermo-compressive and ultrasonic), penetration of molten nanofabric within the main carbon fiber bed was achieved. Nevertheless, welds through thermo-compression seemed to be more coherent and even, compared to welds through ultrasonic welding.

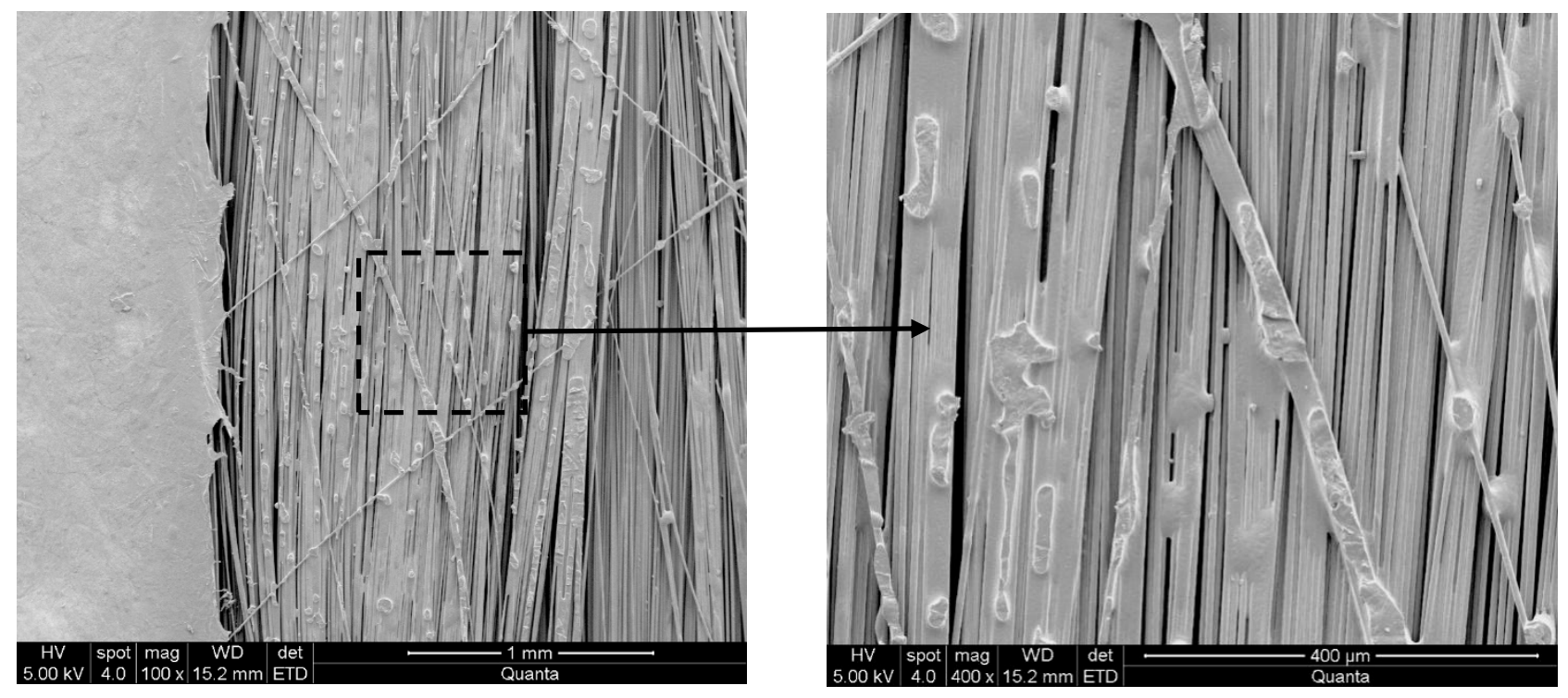

(a)

(b)

Figure 11. (a) SEM image of the weld. (b) Magnification of the dotted area. Circles in (b) indicate areas of molten nanofabric coating the carbon fiber tows. 


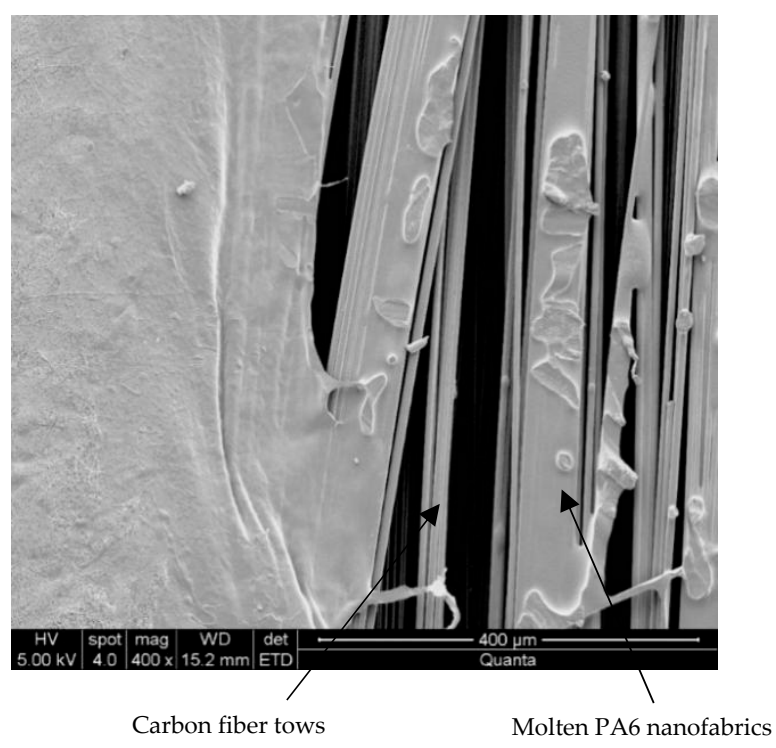

(a)

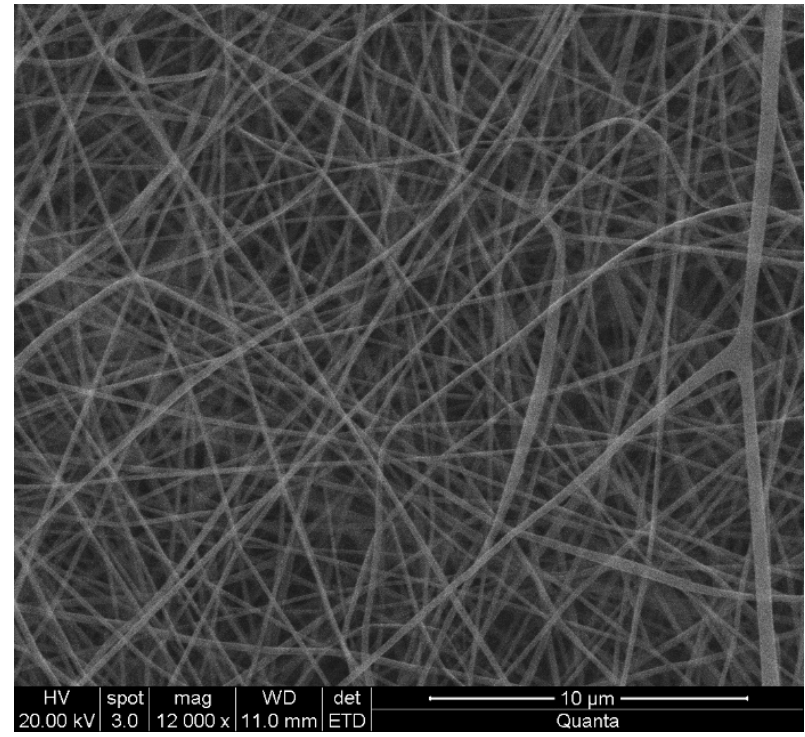

(b)

Figure 12. SEM imaging of (a) the interface between the weld and the adjacent nanofabric and (b) the nanofabric structure prior to consolidation.

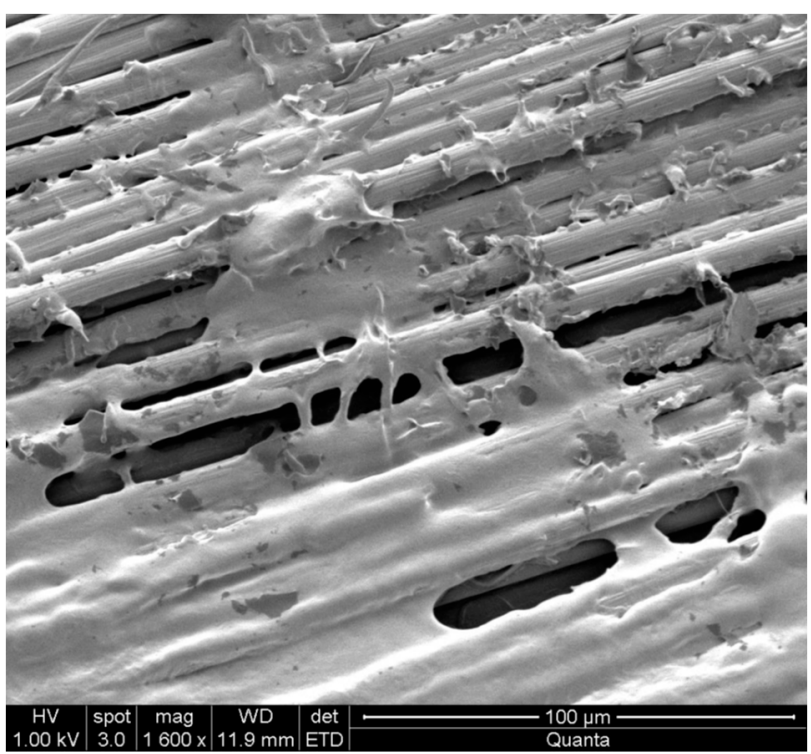

(a)

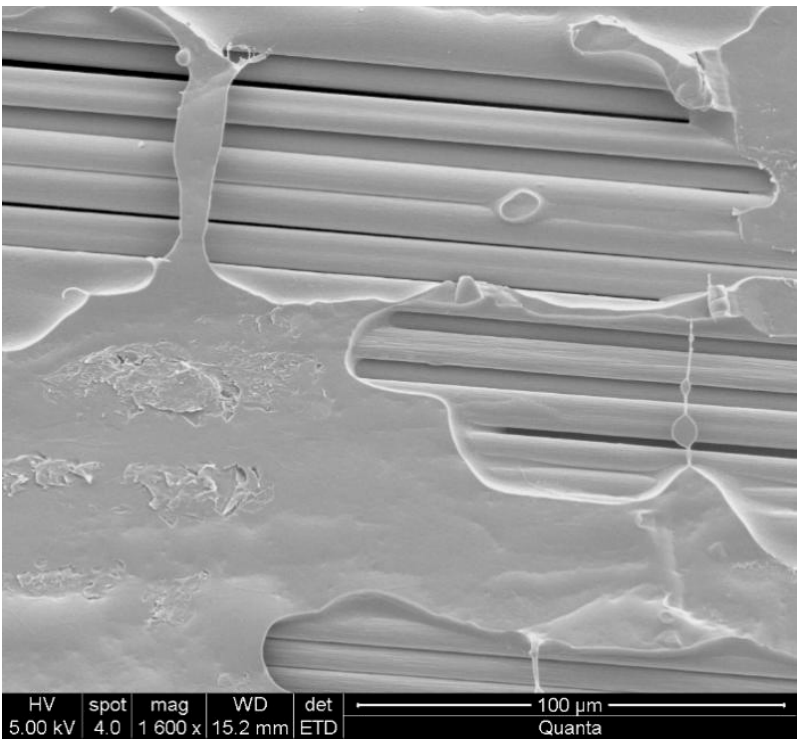

(b)

Figure 13. (a) SEM imaging of the weld consolidated via ultrasonic welding, (b) compared with the weld following thermo-compressive consolidation.

3.3. Mechanical Performance Comparison between UW and Thermo-Compressive Consolidation Nanofiber Enhanced Technical Fabrics

The mechanical performance of the CFRPs using thermo-compressively consolidated nanofiber enhanced technical fabrics (TCC-NanoWeld) was compared that of CFRPs using the proprietary nanofiber enhanced technical fabrics (UW-NanoWeld) consolidated using ultrasonic consolidation. For each mechanical property at least six specimens of each composite were tested. The scope of the paper was to compare the two methods and not the improvement/reinforcement compared to the baseline. As demonstrated in Figure 14, 
TCC-NanoWeld CFRPs exhibited higher interlaminar fracture toughness as compared to the UW-NanoWeld CFRPs. Interlaminar fracture toughness was calculated using three data reduction methods: a modified beam theory (MBT), a compliance calibration method (CC), and a modified compliance calibration method (MCC). Interlaminar fracture toughness of the thermo-consolidated set of specimens increased irrespective of the data reduction method used. Similarly, both flexural (Figure 15) and compressive properties (Figure 16) demonstrated increase when thermo-compressive consolidation was utilized. Conventional fabrics (not high modulus) and general-purpose resins were employed in this study. Thus, the reported flexural and compressive strengths were not as high as other unidirectional composites in the literature. Conventional carbon fibers and epoxy resins were selected as the focus was to compare the two fabric consolidation methods. This could be attributed to the adequate penetration of the molten nanofabric at the welding lines within the main fiber bed (in this case, carbon). Another observation in ultrasonic welded structures is a discontinuity along and on the side of the welding line with the rest of the (nonmelted) nanofabric. In the case of welded structures through thermo-compression, such discontinuity is rare [11]. As discussed above, the pillar of nanofiber enhanced technical fabric performance is its multiscale nature, providing a successful load transfer mechanism. In the presented results, it is apparent that continuous welding structures resulting from thermo-compressive consolidation outperformed the ultrasonic welding ones due to their continuous multiscale nature, biomimicking the internal structure of a feather [1].

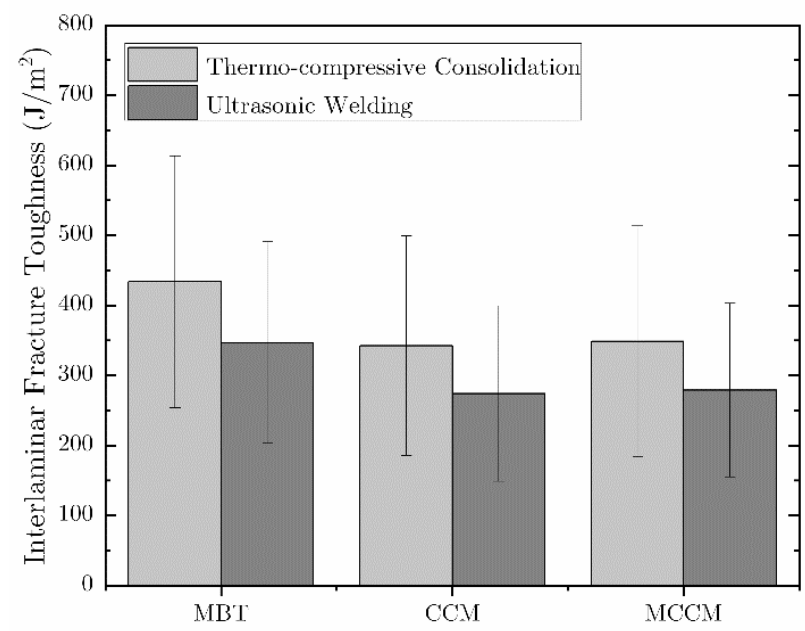

Figure 14. Mode-I interlaminar fracture toughness $\left(\mathrm{J} / \mathrm{m}^{2}\right)$ plotted against the calculation method employed. Modified beam theory (MBT), compliance calibration method (CC), and modified compliance calibration method (MCC) were employed for the two sets of CFRPs tested (thermo-compressive consolidation and ultrasonic welding). 


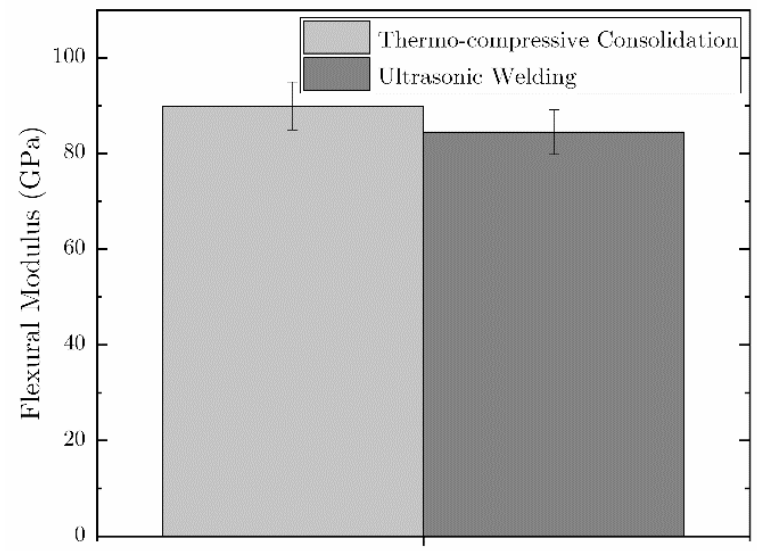

(a)

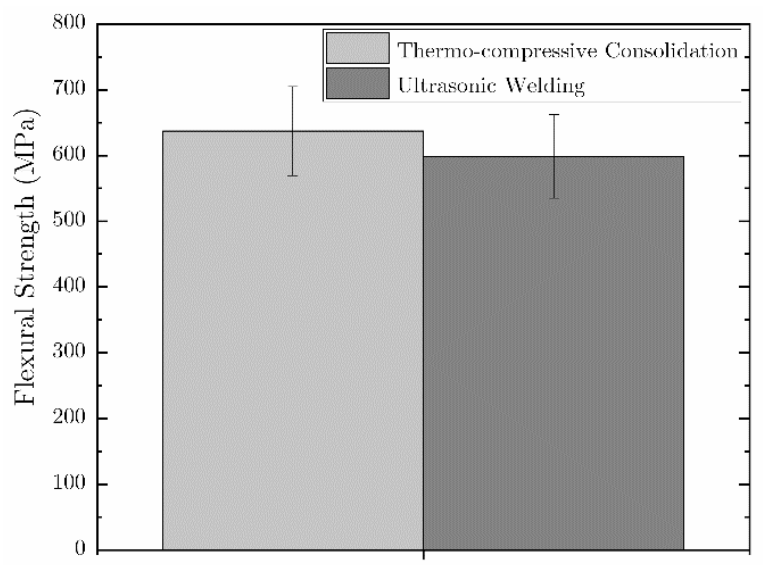

(b)

Figure 15. Comparison plots of (a) flexural modulus (GPa) and (b) flexural strength (MPa), measured for CFRP specimens prepared via thermo-compressive consolidation and ultrasonic welding.

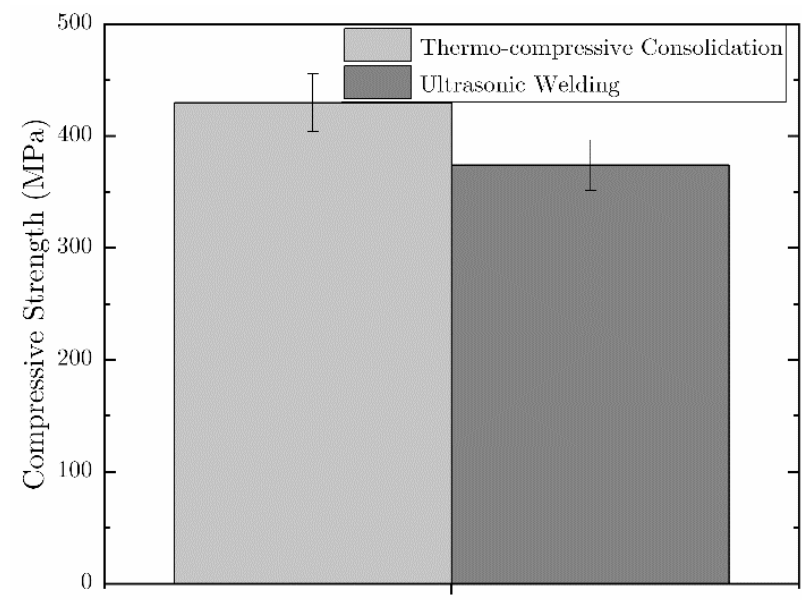

Figure 16. Plots of the CFRPs' compressive strength measured for thermo-compressive consolidation and ultrasonic welding.

\section{Conclusions and Scalability Potential}

This work assessed a new method to increase the capacity of a consolidation machine capable of processing nanofiber enhanced technical fabrics. The new process utilizes heat and pressure to consolidate nonwoven nanofabrics onto carbon fabrics.

- A mechanical design iteration was performed for the development of an efficient industrial prototype that could demonstrate the successful replacement of ultrasonic welding with thermo-compression, providing welding with similar or better level of quality.

- According to simulation results, heat was uniformly transferred through the material layers and consolidation was achieved within $4 \mathrm{~ms}$, indicating that nanofiber enhanced technical fabric production could be accelerated. This helps set the production speed of the process, identifying an effective window of line speed and temperature combinations for processing. In addition, due to the small scale of materials, the transient heat transfer process appeared to be insensitive to their individual properties. This observation is mainly attributed to the particular set of nonwoven nanofabric materials without carbon nanoparticles considered in this study.

In contrast to ultrasonic welding, the new process achieved faster (in terms of production speed) and more uniform dissipation of heat through the nanofabric, producing continuous welding lines and avoiding discontinuities that stem from the welding pat- 
tern in the case of ultrasonic welding, that might cause potential detrimental effects in mechanical performance of composites.

The operating principle of the prototype solution was deemed successful in mitigating the bottleneck of ultrasonic welding processing. A thermo-compression configuration system was employed to consolidate nanofabrics onto a carbon fiber bed. In the next phase of industrialization, this solution could be further scaled up by utilizing heated press rolls with protruding rings instead of heated plates, which can be adapted to a roll-to-roll configuration. In addition, ceramic materials with embedded heating elements could replace the aluminum heat plates to minimize losses and fluctuations, while electromechanical actuators could be added and connected to the control system.

\section{Patents}

Drakonakis VM, Sofocleous K. Process for making hybrid (fiber-nanofiber) textiles through efficient fiber-to-nanofiber bonds comprising novel effective load-transfer mechanisms. World Intellectual Property Organization International Bureau; WO 2018/099910 $\mathrm{Al}, 2016$.

Author Contributions: Conceptualization, A.E., V.D.; methodology and investigation, A.E., K.L. and M.G.; simulation performance and analysis, E.S.; scanning electron microscopy and interpretation, L.K., G.C.; mechanical testing and interpretation, O.M., S.Y.; writing—review and editing, C.D.; supervision, V.D. All authors have read and agreed to the published version of the manuscript.

Funding: This work was co-funded by the European Regional Development Fund and the Republic of Cyprus through the Research and Innovation Foundation (Project: ENTERPRISES/0618/0051 \& INNOVATE/0719/0011).

Institutional Review Board Statement: Not Applicable.

Informed Consent Statement: Not Applicable.

Data Availability Statement: In this section, please provide details regarding where data supporting reported results can be found, including links to publicly archived datasets analyzed or generated during the study. Please refer to suggested Data Availability Statements in section "MDPI Research Data Policies" at https:/ / www.mdpi.com/ethics (accessed on 22 April 2021). You might choose to exclude this statement if the study did not report any data.

Conflicts of Interest: Authors declare no conflict of interest.

\section{References}

1. Drakonakis, V.M.; Velisaris, C.N.; Seferis, J.C.; Doumanidis, C.C. Feather-inspired carbon fiber reinforced poly-mers with nanofibrous fractal interlayer. Polym. Composites. 2016, 37, 168-181. [CrossRef]

2. Kostopoulos, V.; Baltopoulos, A.; Karapappas, P.; Vavouliotis, A.; Paipetis, A. Impact and after-impact properties of carbon fibre reinforced composites enhanced with multi-wall carbon nanotubes. Compos. Sci. Technol. 2010, 70, 553-563. [CrossRef]

3. Vlasveld, D.; Bersee, H.; Picken, S. Nanocomposite matrix for increased fibre composite strength. Polymer 2005, 46, 10269-10278. [CrossRef]

4. Liu, W.; Zhang, S.; Hao, L.; Yang, F.; Jiao, W.; Li, X.; Wang, R. Fabrication of carbon nanotubes/carbon fiber hybrid fiber in industrial scale by sizing process. Appl. Surf. Sci. 2013, 284, 914-920. [CrossRef]

5. Wang, B.-C.; Zhou, X.; Ma, K.-M. Fabrication and properties of CNTs/carbon fabric hybrid multiscale composites processed via resin transfer molding technique. Compos. Part B Eng. 2013, 46, 123-129. [CrossRef]

6. Zhang, H.; Liu, Y.; Kuwata, M.; Bilotti, E.; Peijs, T. Improved fracture toughness and integrated damage sensing capability by spray coated CNTs on carbon fibre prepreg. Compos. Part A Appl. Sci. Manuf. 2015, 70, 102-110. [CrossRef]

7. Wu, H.; Drzal, L.T. Graphene nanoplatelet paper as a light-weight composite with excellent electrical and thermal conductivity and good gas barrier properties. Carbon 2012, 50, 1135-1145. [CrossRef]

8. Wang, Z.; Liang, Z.; Wang, B.; Zhang, C.; Kramer, L. Processing and property investigation of single-walled carbon nanotube (SWNT) buckypaper/epoxy resin matrix nanocomposites. Compos. Part A Appl. Sci. Manuf. 2004, 35, 1225-1232. [CrossRef]

9. Latko, P.; Kozera, R.; Salinier, A.; Boczkowska, A. Non-woven veils manufactured from polyamides doped with carbon nano-tubes. Fibres Text. East. Eur. 2013, 21, 45-49.

10. Drakonakis, V.M.; Sofocleous, K. Process for Making Hybrid (Fiber-Nanofiber) Textiles through Efficient Fiber-to-Nanofiber Bonds Comprising Novel Effective Load-Transfer Mechanisms. World Intellectual Property Organization International Bureau. U.S. Patent Application No. 16/464,527, 29 November 2016. 
11. Loizou, K.; Evangelou, A.; Marangos, O.; Koutsokeras, L.; Chrysafi, I.; Yiatros, S.; Constantinides, G.; Zaoutsos, S.; Drakona-kis, $\mathrm{V}$. Assessing the performance of electrospun nanofabrics as potential interlayer reinforcement materials for fi-ber-reinforced polymers. Compos. Adv. Mater. 2021, 30. [CrossRef]

12. Troughton, M.J. Handbook of Plastics Joining: A Practical Guide; William Andrew: Norwich, CT, USA, 2008.

13. Market Research Report CH 3185. 2020. Available online: https:/ /www.marketsandmarkets.com/pdfdownloadNew.asp?id=20 0051282 (accessed on 22 April 2021).

14. Polymers: Characteristics and Compatibility for Ultrasonic Assembly. Available online: https:/ /www.beckmannconverting.com/ img/technologies/branson_PW-01CharComp-474294.pdf (accessed on 6 May 2021).

15. Alloys, H.S.A.P.M. Properties and Selection: Nonferrous Alloys and Special-Purpose Materials; ASM International: Novelty, OH, USA, 1992; Volume 2.

16. Pradere, C.; Batsale, J.; Goyhénèche, J.; Pailler, R.; Dilhaire, S. Thermal properties of carbon fibers at very high temperature. Carbon 2009, 47, 737-743. [CrossRef]

17. Zink, B.L.; Pietri, R.; Hellman, F. Thermal Conductivity and Specific Heat of Thin-Film Amorphous Silicon. Phys. Rev. Lett. 2006, 96, 055902. [CrossRef] [PubMed]

18. Hibiya, T.; Fukuyama, H.; Tsukada, T.; Watanabe, M. Thermophysical Properties of Molten Silicon. In Crystal Growth Technology: From Fundamentals and Simulation to Large-scale Production; Wiley-VCH Verlag GmbH \& Co. kGaA: Weinheim, Germany, 2008.

19. Kwon, Y.-J.; Park, J.-B.; Jeon, Y.-P.; Hong, J.-Y.; Park, H.-S.; Lee, J.-U. A Review of Polymer Composites Based on Carbon Fillers for Thermal Management Applications: Design, Preparation, and Properties. Polymers 2021, 13, 1312. [CrossRef]

20. Keshtkar, M.; Mehdipour, N.; Eslami, H. Thermal conductivity of polyamide-6,6/carbon nanotube composites: Ef-fects of tube diameter and polymer linkage between tubes. Polymers 2019, 11, 1465. [CrossRef]

21. Sabetzadeh, N.; Bahrambeygi, H.; Rabbi, A.; Nasouri, K. Thermal conductivity of polyacrylonitrile nanofibre web in various nanofibre diameters and surface densities. Micro Nano Lett. 2012, 7, 662. [CrossRef]

22. Bard, S.; Schönl, F.; Demleitner, M.; Altstädt, V. Influence of Fiber Volume Content on Thermal Conductivity in Transverse and Fiber Direction of Carbon Fiber-Reinforced Epoxy Laminates. Materials 2019, 12, 1084. [CrossRef] [PubMed]

23. Bama, G.K.; Devi, P.I.; Ramachandran, K. Structural and thermal properties of PVDF/PVA blends. J. Mater. Sci. 2009, 44, 1302-1307. [CrossRef]

24. Dos Santos, W.N.; Iguchi, C.Y.; Gregorio Jr, R. Thermal properties of poly (vinilidene fluoride) in the temperature range from 25 to 210 C. Polym. Test. 2008, 27, 204-208. [CrossRef] 